\title{
Isolation and characterization of Listeria monocytogenes from environmental and clinical sources by culture and PCR-RFLP methods
}

\author{
Hossein Meghdadi ${ }^{1}$, Azar Dokht Khosravi ${ }^{1,2^{*}}$, Ahmad Farajzadeh Sheikh ${ }^{1,3}$, Ameneh Alami, \\ Nerssy Nassirabady ${ }^{1}$
}

${ }^{1}$ Department of Microbiology, Faculty of Medicine, Ahvaz, Jundishapur University of Medical Sciences, Ahvaz, Iran

${ }^{2}$ Infectious and Tropical Diseases Research Center, Health Research Institute, Ahvaz Jundishapur University of Medical Sciences, Ahvaz, Iran

${ }^{3}$ Cell and Molecular Research Center, Ahvaz Jundishapur University of Medical Sciences, Ahvaz, Iran

Received: August 2018, Accepted: December 2018

\begin{abstract}
Background and Objectives: Due to the widespread distribution of Listeria monocytogenes in environmental and animal sources and serious clinical complications in human, this study was aimed to isolate L. monocytogenes from water and clinical specimens by culture and PCR methods and to investigate the presence of hlyA and inlA virulence genes.

Materials and Methods: Water and clinical samples of vaginal and fecal were screened for the presence of $L$. monocytogenes by phenotypic and standard biochemical tests. PCR amplification was performed on extracted DNA using primers based on the hlyA and inlA genes. A 733-bp fragment of inlA gene was used for investigation of polymorphism using RFLP analysis.

Results: In total, 45 phenotypically and molecularly confirmed L. monocytogenes strains were isolated from different sources including 30 (16.7\%) from water, 9 (11.3\%) from vaginal swabs and 6 (7.5\%) from fecal samples. RFLP analysis of PCR products using AluI and Tsp509I restriction enzymes, generated two profiles with 8 to 10 bands ranging in size from 15 to $210 \mathrm{bp}$. The majority of water and clinical isolates were classified in profile 2.

Conclusion: We demonstrated 45 L. monocytogenes isolates from tested water and clinical samples by phenotypic and molecular tests. The majority of the isolates were classified in the same RFLP profile, showing the water as a potential source of clinical complications in patients in the region of study.
\end{abstract}

Keywords: Listeria monocytogenes; Genotyping; Restriction enzyme; Polymorphism

*Corresponding author: Azar Dokht Khosravi, Ph.D, Department of Microbiology, Faculty of Medicine, Ahvaz Jundishapur University of Medical Sciences, Ahvaz, Iran; Infectious and Tropical Diseases Research Center, Health
Research Institute, Ahvaz Jundishapur University of Medical Sciences, Ahvaz, Iran.

Telefax: +98 6133738392

Email: azarkhosravi69@gmail.com 


\section{INTRODUCTION}

Listeria monocytogenes is a Gram-positive, non-sporulating, intracellular bacillus, with ubiquitous presence in land and water environments, feces, vegetables and gastrointestinal tracts $(1,2)$. The organism was first described by Murray et al., and named "Bacterium monocytogenes", due to the characteristic of monocytosis in infected laboratory animals, and was renamed "Listerella monocytogenes" by Pirie in 1940 (3, 4). Due to its psychrophilic nature, it can grow within a wide range of temperatures $\left(-1.5\right.$ to $\left.50^{\circ} \mathrm{C}\right)$, and therefore grows easily in the water ecosystem (2). Additionally, municipal sewage sludge which is spread onto agricultural lands, contains many pathogens including L. monocytogenes, therefore, agricultural products and ultimately livestock products are contaminated with this organism (5).

The presence of L. monocytogenes in water may be a cause of listeriosis in human and animals (6). The microorganism is causing fatal infections such as encephalitis, sepsis and meningitis in immune deficient patients and abortion in pregnant women $(1,7,8) . L$. monocytogenes is a food-borne pathogen, its incidence and growth in foods, contribute to outbreaks of listeriosis (9). The presence of the organism in pregnancy, may be asymptomatic or associated with vaginal infection in women and represents many risks such as stillbirth, abortion or, serious consequences in neonate, including early onset with bacteremia, pneumonia, conjunctivitis and skin lesions, or late onset with meningitis $(10,11)$.

There is strongly association between antigenic compounds of Listeria spp. and their pathogenicity, which also causes heterogeneity in virulence of $L$. monocytogenes between food and clinical strains (12). The pathophysiology of Listerial infection is associated with adherence and invasion of the gastrointestinal epithelium by the organism, which is mainly mediated by internalin A (InlA), and internalin B (InlB) (13). It has been proved that InlA fragment contributes to the invasiveness of L. monocytogenes and could differentiate potentially invasive bacteria from noninvasive strains (14). Moreover, pore-forming hemolysin listeriolysin $\mathrm{O}(h l y A)$, is required for virulence of L. monocytogenes and is only found in virulent strains (15).

Due to the widespread distribution of L. monocytogenes in environmental and animal sources and serious clinical complications in human, this study was aimed to isolate L. monocytogenes from different parts of Karun River as the largest water source in Khuzestan province, Iran, and also from clinical specimens by culture and PCR methods. Moreover, the presence of $h l y A$ and inlA virulence genes and the relationship between environmental and clinical samples were also investigated by PCR-Restriction Fragment Length Polymorphism (RFLP) techniques.

\section{MATERIALS AND METHODS}

Sampling and isolation of $L$. monocytogenes. A total of 180 water samples from different parts of Karun River in Khuzestan province, Iran, were collected from March to May 2016. The initial proposal of the work was approved by the Institutional Review Board (IRB) and Ethics Committee of the Ahvaz Jundishapur University of Medical Sciences, Iran, and necessary permission was received for the work. Isolation of L. monocytogenes from water samples was performed according to MFHBP-30 method (16), with some modifications. In brief, $100 \mathrm{ml}$ of water was filtered through $0.45 \mu \mathrm{m}$ pore size filters. The water filters were then transferred into $9 \mathrm{ml}$ of Listeria Enrichment Broth (LEB) (Merck, Germany) and incubated at $30^{\circ} \mathrm{C}$ for 48 hours. One $\mathrm{mL}$ of grown LEB was transferred into a bottle containing $9 \mathrm{~mL}$ of Fraser Listeria Selective Enrichment Broth (Merck, Germany), and incubated at $37^{\circ} \mathrm{C}$ for 24 hours. From Fraser grown medium, $50 \mu 1$ was streaked onto Listeria Chromogenic Agar (Merck, Germany), and incubated at $37^{\circ} \mathrm{C}$ for 24 hours. The blue colonies with white halos were selected for microbiological tests.

The clinical samples were included 80 vaginal swabs and 80 stool specimens, which were collected from women with at least two abortions. Both clinical samples were inoculated into the Listeria Enrichment Broth and processed in the same manner described for water samples.

Identification of the L. monocytogenes was done according to the standard microbiological tests such as catalase, oxidase, $\beta$ haemolysis, motility test at $25^{\circ} \mathrm{C}$, the CAMP assay, and acid production from $\mathrm{xy}-$ lose and rhamnose (17).

DNA extraction and PCR amplification. DNAs 
were extracted from the colonies grown on Chromogenic Agar medium, by High pure PCR Template Preparation Kit (Roche Co., Germany). For amplification of $h l y A$ gene, the set of primers of (F, 5'-GAATGTAAACTTCGGCG-CAATCAG-3') and (R, 5'-GCCGTCGATGATTTGAACTTCATC-3'), were used which amplify a $388 \mathrm{bp}$ fragment of the target gene (18). PCR amplification was performed in a final volume of $25 \mu 1$ containing $10 \times$ PCR buffer, $1.5 \mathrm{mM} \mathrm{MgCl}_{2}, 10 \mathrm{mM}$ dNTPs, $0.5 \mathrm{mM}$ of each primer, $1.5 \mathrm{U}$ Taq polymerase and $5 \mu \mathrm{l}$ of template DNA. All the reagents were purchased from Qiagen, Hilden, Germany. Amplification was performed on a thermocycler nexus gradient (Eppendorf), and the cycling program consisted of initial denaturation at $95^{\circ} \mathrm{C}$ for $5 \mathrm{~min}$, followed by 30 cycles of denaturation at $95^{\circ} \mathrm{C}$ for $45 \mathrm{~s}$, annealing at $56^{\circ} \mathrm{C}$ for $45 \mathrm{~s}$, extension at $72^{\circ} \mathrm{C}$ for $60 \mathrm{~s}$, and a final extension at $72^{\circ} \mathrm{C}$ for 7 min. For amplification of inlA gene, a set of primers (seq 01: 5' AATCTAGCACCACTGTCGGG 3') and (seq 02: 5'TGTGACCTTCTTTTACGGGC 3') was used to amplify a $733 \mathrm{bp}$ fragment of the target gene (19). The reaction volume and cycling condition were the same as described for the $h l y A$ gene, with the exception of annealing temperature of $52^{\circ} \mathrm{C}$. L. monocytogenes ATCC-764 and Escherichia coli ATCC 25922 were used as positive and negative controls respectively, and were included in each PCR run. The PCR products were analyzed by gel electrophoresis on $2 \%$ agarose gel (w/vol.) containing $0.5 \mathrm{mg} / \mathrm{mL}$ ethidium bromide (Qiagen, Hilden, Germany). The results were recorded using the gel documentation system (Protein Simple, San Jose, CA, USA). A 100bp DNA ladder was used as a size marker (Roche, Germany).

RFLP analysis of inlA. A 733-bp fragment of inlA gene was used for investigation of polymorphism as described by Rousseaux et al. (19), Two restriction endonucleases of AluI and Tsp509I were used for digestion of inlA amplification products. Briefly, $10 \mu \mathrm{l}$ of fresh PCR product was added to $18 \mu$ l nuclease free water, $2 \mu 1$ 10X buffer tango and $1 \mu \mathrm{l}$ restriction enzyme, mixed gently and incubated at $37^{\circ} \mathrm{C}$ for 16 hours, followed by a step of enzyme inactivation at $65^{\circ} \mathrm{C}$ for $20 \mathrm{~min}$. PCR-RFLP fragments were separated by electrophoresis on a $3.5 \%$ agarose gel.

For data analysis, the descriptive statistics, Chisquare and logistics regression tests were performed in SPSS version 16.00.

\section{RESULTS}

From total tested water samples, $30(16.7 \%)$ had a well grown on chromogenic agar, while of 160 samples of vaginal swabs and feces, $9(11.3 \%)$ and $6(7.5 \%)$, were positive in culture respectively. For 45 samples with an initial positive culture, diagnostic microbiological tests were performed, and all isolates were identified as L. monocytogenes on the basis of $\beta$-hemolysis, catalase activity, motility at $25^{\circ} \mathrm{C}$, positive CAMP test, acid production from rhamnosus, and xylose and negative oxidase test. On performing PCR amplification, all 45 samples had a positive result for both hlyA and inlA genes (Figs. 1 and 2).

The restriction enzyme analysis of PCR products using AluI and Tsp509I, generated two profiles with 8 to 10 bands ranging in size from 15 to $210 \mathrm{bp}$ according to Rousseaux et al. (19), For AluI digestion, the majority of water and clinical isolates were grouped in profile 2 as $70 \%, 77.7 \%$ and $88.3 \%$ for water, vaginal and fecal isolates respectively (Table 1).

Digestion by Tsp509I enzyme generated similar grouping, as most of the water and clinical isolates were classified in profile 2 (Fig. 3).

\section{DISCUSSION}

Listeria monocytogenes is isolated from a diversity of several sources, but municipal sewage sludge and water are mainly important in the transmission of this bacterium. L. monocytogenes is colonized in the gastrointestinal tract and vagina, therefore, it can be a potential pathogen and a public health concern. L. monocytogenes infection in pregnant women, increases the risk of abortion, and also it can be transmitted from mother to fetus through the birth canal and create serious hazards for the neonate $(1,10,16)$.

In this study, due to the importance of water in the transmission of L. monocytogenes, water samples from different parts of Karun River were microbiologically screened. Karun River is a large supplier of water for Khuzestan province, so any serious microbial pollution of this river affecting agricultural farms, and people who are living in villages near the river, where they often use water from river directly for drinking.

From total 180 examined water samples, 30 


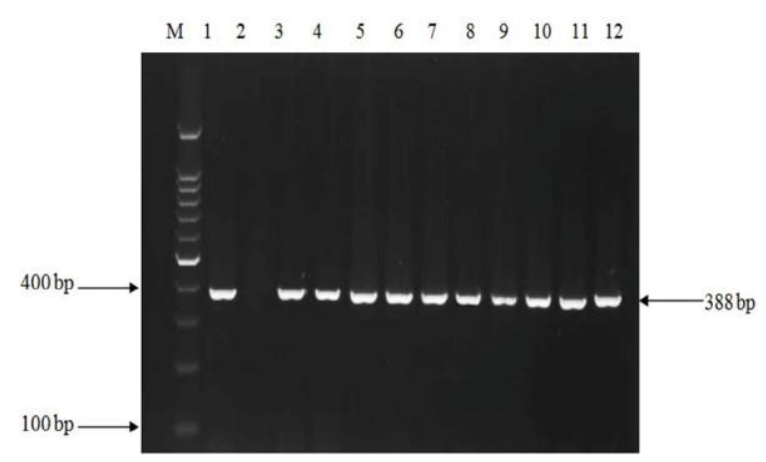

Fig. 1. PCR amplification of the hlyA gene in L. monocytogenes isolates.

M, 100 bp DNA size marker; lane 1, positive control $L$. monocytogenes ATCC (388 bp); Lane 2, negative control; lanes 3 to 7, isolates from water samples; lanes 8 to 10 , isolates from vaginal swabs; and lanes 10 to 12 , isolates from fecal samples.

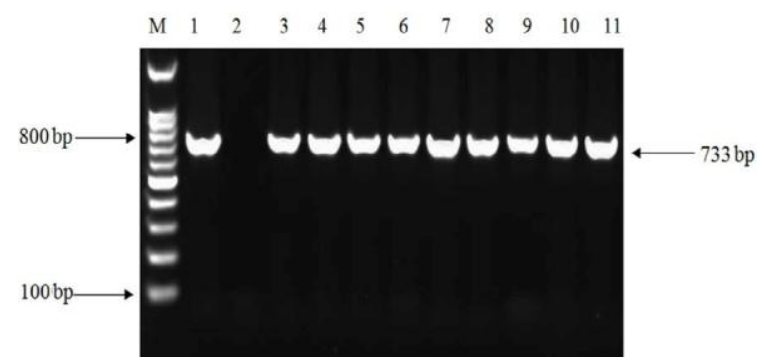

Fig. 2. PCR amplification of inlA gene in L. monocytogenes isolates.

M, 100 bp DNA size marker; lane 1, positive control $L$. monocytogenes ATCC (733 bp); lane 2, negative control; lanes 3 to 6 , isolates from water samples; lanes 7 to 9 , isolates from vaginal swabs; and lanes 10 to 11 , isolates from fecal samples.
(16.7\%), were positive for L. monocytogenes. There are different reports of isolation of L. monocytogenes from rivers, for instance in a study a rate of isolation of $54.5 \%$ has also been reported which was higher than our findings (20).

In addition to water, clinical samples of vaginal swabs and feces were also studied in the present study. Samples of vaginal swabs were collected from women with at least two abortions. Of $80 \mathrm{vag}-$ inal samples, 9 (11.3\%) were positive for L. monocytogenes. This rate was lower in comparison to the rate of $16.6 \%$ in the study of Eslami et al. (21), and $14.2 \%$ reported by Pournajaf et al., both from Iran (22). In both latter studies, the reason for the difference is the different geographic locations studied. In the current study and other similar studies, the prevalence of L. monocytogenes is reported in women with abortion history. As other investigators statement, during pregnancy, due to the increase in

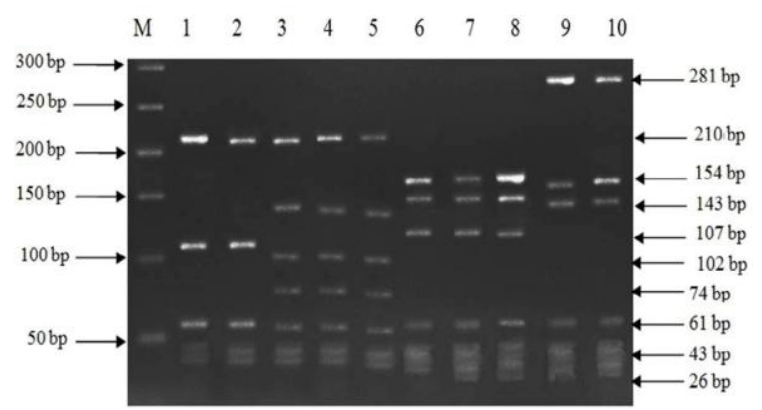

Fig. 3. RFLP profiles of L. Monocytogenes isolates after digestion with AluI and Tsp5091 enzymes.

M, 50 bp molecular size marker;

AluI digestion results: lanes 1 and 2, profile 2; lanes 3 to 5, profile 3.

Tsp5091 digestion results: lanes 6 to 8 , profile 2; lanes 9 and 10 , profile 3.

Table 1. RFLP profiles of water and clinical isolates digested with AluI and Tsp5091 restriction enzymes in the present study

\begin{tabular}{llll}
\hline Restriction profiles & Water isolates No $(\%)$ & Vaginal isolates No $(\%)$ & Fecal isolates No $(\%)$ \\
\hline AluI & $21(70)$ & $7(77.7)$ & $5(83.4)$ \\
Profile 2 & $9(30)$ & $2(22.3)$ & $1(16.6)$ \\
Profile 3 & & & \\
Tsp5091 & $23(76.7)$ & $6(66.7)$ & $4(66.7)$ \\
Profile 2 & $7(23.3)$ & $3(33.3)$ & $2(33.3)$ \\
Profile 3 & & & \\
\hline
\end{tabular}


the amount of progesterone, cellular immunity is weakened and this makes the pregnant women mainly susceptible to intracellular microorganisms like L. monocytogenes (23). In this study, 80 samples of feces were collected which $6(7.5 \%)$ samples had a positive culture. This finding was in concordant to the rate of $8.5 \%$ reported by Pournajaf et al. (22), and $6 \%$ in the study of Lyautey et al., which in both studies L. monocytogenes was isolated from fecal samples (24). In disagreement to our study, lower rate of $0.12 \%$ L. monocytogenes from fecal samples were reported by Sauders et al. in four large metropolitan areas of New York state (25), which the difference in geographical areas may be the reason for this difference.

According to the results from PCR assay, all the positive 45 samples detected by phenotypic tests, including 30 water samples, 9 vaginal swabs and 6 fecal samples had a positive result for both hlyA and inlA genes. In some previous studies, the work was only focused on water samples and no clinical specimens were included to be able to find out the probable correlation between $L$. monocytogenes isolates from water and those from clinical source in view of genetic similarities $(5,16,20)$. In this work, for investigation of a probable link between strains isolated from water sources and clinical specimens, RFLP analysis on inlA were performed. Using endonucleases AluI and Tsp509I, two profiles were generated. The majority of water, vaginal and fecal isolates were classified in profile 2 for both restriction enzyme tested and this demonstrates that water of Karun River, could be the potential source of L. monocytogenes to human infection in the present study. In the study of Rousseaux et al. which amplified inlA fragment was digested by endonucleases AluI and Tsp509I, five profiles were generated for AluI, and three profiles for Tsp509I endonucleases (19).

In the current study, 45 L. monocytogenes isolates were cultured from tested water and clinical samples and confirmed by phenotypic and molecular tests. The majority of the isolates were classified in profile 2 as RFLP analysis revealed, showing the clinical isolates were mainly originated from water. Due to the invasive nature of L. monocytogenes, and the various diseases that this bacterium causes in animals and humans especially pregnant women, further studies on L. monocytogenes appear to be necessary.

\section{ACKNOWLEDGEMENTS}

This work was financially supported by a Grant (OG-94102) from Research affairs, Ahvaz Jundishapur University of Medical Sciences, Ahvaz, Iran. We are grateful the Infectious and Tropical Diseases Research Center of Ahvaz Jundishapur University of Medical Sciences, Ahvaz, Iran, for approval of the work.

\section{REFERENCES}

1. Ramaswamy V, Cresence VM, Rejitha JS, Lekshmi MU, Dharsana KS, Prasad SP, et al. Listeria--review of epidemiology and pathogenesis. J Microbiol Immunol Infect 2007; 40:4-13.

2. O'Connell RM, Saha SK, Vaidya SA, Bruhn KW, Miranda GA, Zarnegar B, et al. Type I interferon production enhances susceptibility to Listeria monocytogenes infection. J Exp Med 2004;200: 437-445.

3. Farber JM, Peterkin PI. Listeria monocytogenes, a foodborne pathogen. Microbiol Rev 1991;55:476-511.

4. Cone LA, Somero MS, Qureshi FJ, Kerkar S, Byrd RG, Hirschberg JM, et al. Unusual infections due to Listeria monocytogenes in the southern California desert. Int $J$ Infect Dis 2008; 12:578-581.

5. Garret N, Picard-Bonnaud F, Pourcher AM. Occurrence of Listeria spp. and L. monaytogenes in sewage sludge used for land application: effect of dewatering, liming and storage in tank on survival of Listeria species. FEMS Immunol Med Microbiol 2003; 35:275-283.

6. Wing EJ, Gregory SH. Listeria monocytogenes: clinical and experimental update. J Infect Dis 2002;185:S18-24.

7. Mateus T, Silva J, Maia RL, Teixeira P. Listeriosis during pregnancy: A public health concern. ISRN $\mathrm{Ob}$ stet Gynecol 2013; 2013:851712.

8. Jeffers GT, Bruce JL, McDonough PL, Scarlett J, Boor KJ, Wiedmann M. Comparative genetic characterization of Listeria monocytogenes isolates from human and animal listeriosis cases. Microbiology 2001;147:1095-1104.

9. Jemmi T, Stephan R. Listeria monocytogenes: foodborne pathogen and hygiene indicator. Rev Sci Tech 2006; 25:571-580.

10. Borges SF, Silva JG, Teixeira PC. Survival and biofilm formation of Listeria monocytogenes in simulated vaginal fluid: influence of $\mathrm{pH}$ and strain origin. FEMS Immunol Med Microbiol 2011; 62:315-320.

11. Delgado AR. Listeriosis in pregnancy. J Midwifery Womens Health 2008; 53: 255-259.

12. Dussurget O. New insights into determinants of Liste- 
ria monocytogenes virulence. Int Rev Cell Mol Biol 2008; 270:1-38

13. Schuppler M, Loessner MJ. The opportunistic pathogen Listeria monocytogenes: pathogenicity and interaction with the mucosal immune system. Int J Inflam 2010; 2010:704321.

14. Tamburro M, Ripabelli G, Fanelli I, Grasso GM, Sammarco ML. Typing of Listeria monocytogenes strains isolated in Italy by inlA gene characterization and evaluation of a new cost-effective approach to antisera selection for serotyping. J Appl Microbiol 2010; 108:1602-1611.

15. Churchill RL, Lee H, Hall JC. Detection of Listeria monocytogenes and the toxin listeriolys in $\mathrm{O}$ in food. $J$ Microbiol Methods 2006;64:141-170.

16. Lyautey E, Lapen DR, Wilkes G, McCleary K. Distribution and characteristics of Listeria monocytogenes isolates from surface waters of the south nation river watershed, Ontario, Canada. Appl Environ Microbiol 2007;73:5401-5410.

17. Procop GW, Church DL, Hall GS, Janda WM, Koneman EW, Schreckenberger PC, et al. (2017). Koneman's Color Atlas and Textbook of Diagnostic 7th ed. Philadelphia: Wolters Kluwer, pp. 845-853.

18. Aznar R, Alarcon B. PCR detection of Listeria monocytogenes: a study of multiple factors affecting sensitivity. J Appl Microbiol 2003; 95:958-966.

19. Rousseaux S, Olier M, Lemaitre JP, Piveteau P, Guzzo J. Use of PCR-Restriction fragment length polymorphism of inlA for rapid screening of Listeria monocy- togenes strains deficient in the ability to invade Caco-2 cells. Appl Environ Microbiol 2004; 70: 2180-2185.

20. Odjadjare EE, Obi LC, Okoh AI. Municipal waste water effluents as a source of listerial pathogens in the aquatic milieu of the Eastern Cape province of south Africa: a concern of public health importance. Int J Environ Res Public Health 2010;7:2376-2394.

21. Eslami G, Goudarzi H, Ohadi E, Taherpour A, Pourkaveh B, Taheri S. Identification of Listeria monocytogenes virulence factors in women with abortion by polymerase chain reaction. Arch Clin Infect Dis 2014; 9(3): e19931.

22. Pournajaf A, Rajabnia R, Sedighi M, Kassani A, Moqarabzadeh V, Lotfollahi L, et al. Prevalence, and virulence determination of Listeria monocytogenes strains isolated from clinical and non-clinical samples by multiplex polymerase chain reaction. Rev Soc Bras Med Trop 2016;49:624-627.

23. Leber A, Zenclussen ML, Teles A, Brachwitz N, Casalis P, El-Mousleh T, et al. Pregnancy: tolerance and suppression of immune responses. Methods Mol Biol 2011;677:397-417.

24. Lyautey E, Hartmann A, Pagotto F, Tyler K, Lapen DR, Wilkes G, et al. Characteristics and frequency of detection of fecal Listeria monocytogenes shed by livestock, wildlife, and humans. Can J Microbiol 2007; 53:11581167.

25. Sauders BD, Pettit D, Currie B, Suits P, Evans A, Stellrecht K, et al. Low prevalence of Listeria monocytogenes in human stool. J Food Prot 2005;68:178-181. 